\title{
Decreasing the minimum length criterion for an episode of hypomania: evaluation using self-reported data from patients with bipolar disorder
}

\author{
Michael Bauer - Tasha Glenn • Natalie Rasgon • Wendy Marsh • \\ Kemal Sagduyu • Paul Grof • Martin Alda • Greg Murray • Rodrigo Munoz • \\ Danilo Quiroz $\cdot$ Rita Bauer · Burkhard Jabs • Peter C. Whybrow
}

Received: 23 July 2010/ Accepted: 23 December 2010/Published online: 26 January 2011

(C) The Author(s) 2011. This article is published with open access at Springerlink.com

\begin{abstract}
Brief hypomania lasting less than 4 days may impair functioning and help to detect bipolarity. This study analyzed brief hypomania that occurred in patients with bipolar disorder who were diagnosed according to the DSM-IV criteria. Daily self-reported mood ratings were obtained from 393 patients (247 bipolar I and 146 bipolar II) for 6 months (75,284 days of data, mean 191.6 days).
\end{abstract}

\section{Bauer $(\square)$. B. Jabs}

Department of Psychiatry and Psychotherapy,

Universitätsklinikum Carl Gustav Carus, Technische Universität

Dresden, Germany Fetscherstr. 74, 01307 Dresden, Germany

e-mail: michael.bauer@uniklinikum-dresden.de

T. Glenn

ChronoRecord Association, Inc., PO Box 3501,

Fullerton, CA 92834, USA

URL: http://www.chronorecord.org

\section{N. Rasgon}

Department of Psychiatry and Behavioral Sciences,

Stanford School of Medicine, Palo Alto, CA, USA

\section{W. Marsh}

Department of Psychiatry, University of Massachusetts,

55 Lake Avenue North, Worcester, MA 01655, USA

\section{K. Sagduyu}

Department of Psychiatry, University of Missouri Kansas City

School of Medicine, Kansas City, MO, USA

\section{K. Sagduyu}

PO Box 23430, Stanley, KS 66283, USA

P. Grof

Mood Disorders Center of Ottawa, 1929 Russell Road,

K1G 4G3 Ottawa, Canada

P. Grof

Department of Psychiatry, University of Toronto,

Toronto, ON, Canada
Episodes of hypomania were calculated using a 4, 3, 2, and single day length criterion. Brief hypomania occurred frequently. With a decrease in the minimum criterion from 4 days to 2 days, there were almost twice as many patients with an episode of hypomania (102 vs. 190), and more than twice as many episodes (305 vs. 863). Single days of hypomania were experienced by $271(69 \%)$ of the sample.

\section{Alda}

Department of Psychiatry, Dalhousie University,

5909 Veteran's Memorial Lane, QEII Health Sciences Centre, Halifax, NS B3H 2E2, Canada

\section{G. Murray}

Faculty of Life and Social Sciences,

Swinburne University of Technology, PO Box 218,

John St., Hawthorn 3122 Melbourne, Victoria, Australia

\section{R. Munoz}

Department of Psychiatry, University of California San Diego,

San Diego, CA, USA

D. Quiroz

Mood Disorder Clinic EFESO, Apoquindo 4100 Suite 701,

Santiago 7550112, Chile

\section{R. Bauer}

Department of Psychiatry and Psychotherapy,

University of Regensburg, Universitätsstrasse 84,

Regensburg 93053, Germany

\section{P. C. Whybrow}

Department of Psychiatry and Biobehavioral Sciences,

Semel Institute for Neuroscience and Human Behavior

University of California Los Angeles (UCLA),

300 UCLA Medical Plaza, Los Angeles, CA 90095, USA 
With a 2-day episode length, 33\% of all hypomania remained outside of an episode. There was no significant difference in the percent of hypomanic days outside of an episode between patients with bipolar I and II disorders. There were no significant differences in the demographic characteristics of patients who met the 4-day minimum as compared with those who only experienced episodes of hypomania using a shortened length criterion. Decreasing the minimum length criterion for an episode of hypomania will cause a large increase in the number of patients who experience an episode and in the aggregate number of episodes, but will not distinguish subgroups within a sample who meet the DSM-IV criteria for bipolar disorder. Frequency may be an important dimensional aspect of brief hypomania. Clinicians should regularly probe for brief hypomania.

Keywords Bipolar disorder, hypomania $\cdot$ Brief hypomania $\cdot$ DSM-IV criteria

\section{Introduction}

Many patients with bipolar disorder experience hypomania for periods less than the minimum episode length criterion of 4 days in the DSM-IV [1-4]. There is a need to increase focus on this brief hypomania since even subsyndromal symptoms may impair functioning and diminish the quality of life [5-7]. Additionally, some researchers feel that a shorter length criterion would better reflect the entire spectrum of bipolar disorder, and improve detection of bipolarity in patients with depressive episodes $[2,3,8-10]$. The criteria used to define an episode of hypomania are under revision as part of the ongoing DSM-V review process [11]. Within this context, the primary objective of this study was to characterize brief hypomania lasting less than 4 days that is experienced by patients who meet the DSM-IV criteria for bipolar disorder. The secondary objective was to determine if the patients who experienced an episode of hypomania only when using a shortened criterion were a distinct subgroup from those who met the 4-day criterion during the study period.

We have previously investigated the impact of changing the length criterion for an episode of hypomania from 4 days to 2 using daily self-reported mood ratings from 203 patients who were diagnosed with bipolar disorder using the DSM-IV criteria [4]. As the minimum length criterion for an episode of hypomania decreased, a large increase was found in both the number of patients with episodes and the number of episodes. This study repeated the prior analysis using a larger sample and including a length criterion of a single day.

\section{Methods}

The inclusion criteria were a diagnosis of bipolar disorder by DSM-IV criteria, age 18 years or older, currently receiving pharmacological treatment and a willingness to record mood daily for 5 months using computer software in their native language. All participants volunteered, provided informed written consent, and received treatment as usual throughout the study. The naturalistic approach with minimal exclusion criteria was selected to better reflect routine clinical practice and patient heterogeneity. The diagnosis of bipolar disorder was made by the prescribing psychiatrist in a clinical interview. Additional details about the ChronoRecord study were published previously [12]. Patients from our prior study [4] were included in this analysis, although some provided additional data.

\section{Daily mood ratings}

Patients provided a daily mood rating using the previously validated ChronoRecord software that was installed on a home computer [13, 14]. A 100-unit visual analogue scale was used to rate mood between the most extreme mania and depression the patient ever experienced. Based upon the validation studies comparing the self-ratings with clinician ratings on the Hamilton Depression Rating Scale (HAMD) and the Young Mania Rating Scale (YMRS) [13, 14], a mood entry less than 40 was considered depression, 40-60 euthymia, and greater than 60 hypomania/mania. A rating of $61-80$ was considered hypomania and $81-100$ was considered mania. The self-ratings of mania reflect activation levels for either euphoric or dysphoric mood [13]. A detailed account of data collection using ChronoRecord is provided elsewhere [12-14].

\section{Statistics}

The demographic characteristics, mood ratings, and psychotropic medications taken by the patients were obtained. To be considered using a medication, a patient had to take any dose of the drug for at least $50 \%$ of the days. Episodes of hypomania and depression were determined using a published algorithm to calculate episodes from daily selfreported mood data based on the DSM-IV criteria [15]. Episodes of hypomania were also calculated while varying the minimum duration between 3,2 , and 1 days. The demographic characteristics and medications taken were compared between patients with bipolar I and bipolar II disorder, using the Pearson 2-sided $X^{2}$ test for distributions and the independent sample 2-sided $t$ test for mean values. For the subgroup analysis, the demographic characteristics 
and medications taken were compared between patients with one or more episode of hypomania using the 4-day length criterion, and those with one or more episode of hypomania only if a shorter criterion was used (4-day vs. 3-day length, 4-day vs. 2-day length, and 4 day vs. 1-day length). A $P$ value of less than 0.05 was considered statistically significant for all tests. SPSS 18.0 was used for all calculations.

\section{Results}

Data were available from 410 patients, 247 with a diagnosis of bipolar I disorder, 146 with a diagnosis of bipolar II disorder, and 17 with a diagnosis of bipolar NOS. Since the group with a diagnosis of bipolar NOS was so small, they were excluded from this analysis leaving 393 patients.
The 393 patients returned 75,284 days of data (mean 191.6 days). Of the 393 patients $266(68 \%)$ were recruited from a university mood clinic, and 127 (32\%) from a private practice. The demographic characteristics of those with BP I and BP II disorder are shown in Table 1. Patients with bipolar I disorder had more hospitalizations ( 2.8 vs. $1.4, P=0.002)$, took antidepressants less frequently (45 vs. $63 \%, P<0.001$ ), lamotrigine less frequently (33 vs. $45 \%, P=0.018$ ), and lithium more frequently (32 vs. $21 \%, P=0.018$ ). No other significant differences in demographic characteristics were found between patients with bipolar I and bipolar II disorder.

The impact of changing the minimum length requirement for an episode of hypomania is shown in detail in Table 2. When the minimum episode length was decreased from 4 to 2 days, the percent of days spent in a hypomanic episode by each patient nearly doubled (4.5-8.2\%), and the number of

Table 1 Comparison of demographics of patients with diagnosis of bipolar I or bipolar II disorder

\begin{tabular}{|c|c|c|c|c|c|}
\hline & \multicolumn{5}{|l|}{ Diagnosis } \\
\hline & Bipolar I $(N=247)$ & Bipolar II $(N=146)$ & Total $(N=393)$ & Degrees of freedom (DF) & $P$ \\
\hline Age (mean years, SD) & $39.4(11.2)$ & $38.2(11.4)$ & $39.0(11.3)$ & $299.1^{\mathrm{a}}$ & 0.299 \\
\hline Age of onset (mean years, SD) & $22.6(9.7)$ & $20.9(10.9)$ & $22.0(10.2)$ & $240.4^{\mathrm{a}}$ & 0.133 \\
\hline Years of illness (mean years, SD) & $16.9(11.1)$ & $17.7(12.3)$ & $17.2(11.5)$ & $241.7^{\mathrm{a}}$ & 0.535 \\
\hline Hospitalizations (mean $N, \mathrm{SD}$ ) & $2.8(4.2)$ & $1.4(3.2)$ & $2.3(3.9)$ & $326.1^{\mathrm{a}}$ & 0.001 \\
\hline Gender & & & & $1^{\mathrm{b}}$ & 0.059 \\
\hline Female $(N, \%)$ & $160(65)$ & $108(74)$ & $268(68)$ & & \\
\hline Male $(N, \%)$ & $87(35)$ & $38(26)$ & $125(32)$ & & \\
\hline Education level & & & & $2^{\mathrm{b}}$ & 0.274 \\
\hline High school $(N, \%)$ & $33(14)$ & $12(9)$ & $45(12)$ & & \\
\hline Some college $(N, \%)$ & $75(33)$ & $45(33)$ & $120(33)$ & & \\
\hline College graduate $(N, \%)$ & $121(53)$ & $79(58)$ & $200(55)$ & & \\
\hline Employment status & & & & $2^{\mathrm{b}}$ & 0.079 \\
\hline Disabled $(N, \%)$ & $66(29)$ & 25 (19) & $91(25)$ & & \\
\hline Working full-time $(N, \%)$ & $102(44)$ & $72(56)$ & $174(49)$ & & \\
\hline Other $(N, \%)$ & $61(27)$ & $33(25)$ & $94(26)$ & & \\
\hline Marital status & & & & $2^{\mathrm{b}}$ & 0.370 \\
\hline Married $(N, \%)$ & $107(46)$ & $66(50)$ & $173(47)$ & & \\
\hline Single $(N, \%)$ & $90(39)$ & $52(39)$ & $142(39)$ & & \\
\hline Divorced $(N, \%)$ & $37(15)$ & $14(11)$ & $51(14)$ & & \\
\hline Number of daily medications (mean $N, \mathrm{SD}$ ) & $2.8(1.6)$ & $2.6(1.5)$ & $2.7(1.6)$ & $322.8^{\mathrm{a}}$ & 0.330 \\
\hline Taking mood stabilizer $(N, \%)$ & $204(83)$ & $111(76)$ & $315(80)$ & $1^{\mathrm{b}}$ & 0.115 \\
\hline Taking lithium $(N, \%)$ & $78(32)$ & $30(21)$ & $108(28)$ & $1^{\mathrm{b}}$ & 0.018 \\
\hline Taking valproate $(N, \%)$ & $49(20)$ & $32(22)$ & $81(21)$ & $1^{\mathrm{b}}$ & 0.622 \\
\hline Taking lamotrigine $(N, \%)$ & $82(33)$ & $66(45)$ & $148(38)$ & $1^{\mathrm{b}}$ & 0.018 \\
\hline Taking antidepressant $(N, \%)$ & $110(45)$ & $92(63)$ & $202(51)$ & $1^{\mathrm{b}}$ & $<0.001$ \\
\hline Taking antipsychotic $(N, \%)$ & $114(46)$ & $57(39)$ & $171(44)$ & $1^{\mathrm{b}}$ & 0.169 \\
\hline Taking benzodiazepine $(N, \%)$ & $51(21)$ & $35(24)$ & $86(22)$ & $1^{\mathrm{b}}$ & 0.441 \\
\hline Taking sleep medication $(N, \%)$ & $18(7)$ & $7(5)$ & $25(6)$ & $1^{\mathrm{b}}$ & 0.328 \\
\hline
\end{tabular}


Table 2 Impact of changing the minimum episode length for hypomania for patients with bipolar disorder

\begin{tabular}{|c|c|c|c|c|c|c|c|c|c|c|}
\hline & \multicolumn{8}{|c|}{ Hypomanic episode minimum length } & \multicolumn{2}{|c|}{$\%$ Change } \\
\hline & \multicolumn{2}{|l|}{4 days } & \multicolumn{2}{|l|}{3 days } & \multicolumn{2}{|c|}{2 days } & \multicolumn{2}{|l|}{1 day } & \multirow[b]{2}{*}{ 4-2 day } & \multirow[b]{2}{*}{$4-1$ day } \\
\hline & $N$ & $\%$ & $N$ & $\%$ & $N$ & $\%$ & $N$ & $\%$ & & \\
\hline \multicolumn{11}{|l|}{ All patients $(N=393)$} \\
\hline Mean percent days in hypomanic episode & & 4.5 & & 5.9 & & 8.2 & & 10.6 & 82 & 136 \\
\hline Mean percent days in depressed episode & & 8.2 & & 8.0 & & 8.0 & & 7.3 & -2 & -11 \\
\hline Number of hypomanic episodes & 305 & & 491 & & 863 & & 2,164 & & 183 & 610 \\
\hline Number of depressed episodes & 303 & & 293 & & 289 & & 264 & & -5 & -13 \\
\hline Number of patients with hypomanic episodes & 102 & 26 & 145 & 37 & 190 & 48 & 271 & 69 & 86 & 166 \\
\hline Number of patients with depressed episodes & 113 & 29 & 114 & 29 & 114 & 29 & 108 & 28 & 1 & -4 \\
\hline \multicolumn{11}{|l|}{ All hypomanic days $(N=6,188)$} \\
\hline Hypomanic days in hypomanic episode & 2,699 & 44 & 3,356 & 54 & 4,169 & 67 & 6,188 & 100 & 54 & 129 \\
\hline Hypomanic days not in hypomanic episode & 3,489 & 56 & 2,832 & 46 & 2,019 & 33 & 0 & 0 & -42 & -100 \\
\hline \multicolumn{11}{|l|}{ All depressed days $(N=15,699)$} \\
\hline Depressed days in depressed episode & 5,988 & 38 & 5,901 & 38 & 5,839 & 37 & 5,578 & 36 & -2 & -7 \\
\hline Depressed days not in depressed episode & 9,711 & 62 & 9,798 & 62 & 9,860 & 63 & 10,121 & 64 & 2 & 4 \\
\hline \multicolumn{11}{|l|}{ All hypomanic days bipolar I $(N=3,772)$} \\
\hline Hypomanic days in hypomanic episode & 1,650 & 44 & 2,046 & 54 & 2,531 & 67 & 3,772 & 100 & 53 & 126 \\
\hline Hypomanic days not in hypomanic episode & 2,122 & 56 & 1,726 & 46 & 1,241 & 33 & 0 & 0 & -42 & -100 \\
\hline \multicolumn{11}{|l|}{ All hypomanic days bipolar II $(N=2,416)$} \\
\hline Hypomanic days in hypomanic episode & 1,049 & 43 & 1,310 & 54 & 1,638 & 68 & 2,416 & 100 & 56 & 130 \\
\hline Hypomanic days not in hypomanic episode & 1,367 & 57 & 1,106 & 46 & 778 & 32 & 0 & 0 & -43 & -100 \\
\hline
\end{tabular}

patients experiencing a hypomanic episode nearly doubled (102-190). When the minimum episode length was decreased to 1 day, the percent of days spent in a hypomanic episode by each patient more than doubled (4.5-10.6\%), and the number of patients experiencing a hypomanic episode was more than 21/2 times greater (102-271).

With a 4-day length requirement, $56 \%$ of reported days of hypomania and $62 \%$ of days of depression occurred outside of an episode. When the length requirement was decreased to 2 days, $33 \%$ of hypomanic days occurred outside of an episode. With a 1-day length requirement, there was a $13 \%$ decrease in depressed episodes for all patients, as the occurrence of brief hypomanic interrupted depressed episodes based on the algorithm.

As the episode length criterion decreased, the pattern of change was very similar for patients with bipolar I and bipolar II disorder. There was no significant difference in the percent of days of hypomania reported outside of an episode between patients with bipolar I and bipolar II disorder whether the minimum length was 4 days $(P=0.173), 3$ days $(P=0.212)$, or 2 days $(P=0.404)$. When the minimum length was 1 day, all hypomania was included in an episode.

With a 4-day length criterion, 102 patients experienced at least one episode of hypomania. With a 3-day length criterion, there were 43 additional patients with at least one episode of hypomania. With a 2-day length criterion, there were 88 additional patients, and with a 1-day length, 169 additional patients. The comparison of the demographic characteristics of the 102 patients who experienced at least one episode of hypomania with a 4-day length, with the additional patients who experienced a hypomanic episode as the length criterion was shortened is shown in Table 3. There was no demographic that was significantly different across all the additional patient groups. As the length criterion decreased, a significantly smaller percentage of patients who had a hypomanic episode were taking antipsychotics (4-day vs. 2 -day, 53 vs. $38 \%, P=0.033$; and 4-day vs. 1 -day, 53 vs. $39 \%, P=0.026)$.

\section{Discussion}

Hypomania lasting less than 4 days occurred frequently in this study of patients diagnosed with bipolar disorder using the DSM-IV criteria. As the minimum length criterion for an episode of hypomania decreased, there was a large increase in both the number of patients experiencing an episode and in the number of episodes. When comparing a 2-day minimum length to a 4-day minimum length, there were almost twice as many patients with an episode of hypomania, and about twice as many episodes. These 
Table 3 Demographics of patients with 4 day hypomanic episodes compared to additional patients with 3, 2, and 1 day hypomanic episodes

\begin{tabular}{|c|c|c|c|c|c|c|c|c|c|c|}
\hline & \multirow{2}{*}{$\begin{array}{l}4 \text { day hypomanic } \\
\text { episode } \\
\text { Patients } \\
(N=102)\end{array}$} & \multicolumn{3}{|c|}{3 day hypomanic episode } & \multicolumn{3}{|c|}{2 day hypomanic episode } & \multicolumn{3}{|c|}{1 day hypomanic episode } \\
\hline & & $\begin{array}{l}\text { Additional } \\
\text { patients } \\
(N=43)\end{array}$ & $\mathrm{DF}$ & $P$ & $\begin{array}{l}\text { Additional } \\
\text { patients } \\
(N=88)\end{array}$ & DF & $P$ & $\begin{array}{l}\text { Additional } \\
\text { patients } \\
(N=169)\end{array}$ & DF & $P$ \\
\hline $\operatorname{Age}^{\mathrm{a}}$ (mean years, SD) & $38.9(11.9)$ & $40.4(9.0)$ & 103.1 & 0.400 & $39.5(11.0)$ & 187.1 & 0.687 & $39.8(11.3)$ & 204.9 & 0.524 \\
\hline Age of onset ${ }^{\mathrm{a}}$ (mean years, SD) & $23.8(11.3)$ & $20.1(10.3)$ & 79.9 & 0.068 & $20.6(10.9)$ & 169.2 & 0.054 & $21.4(10.7)$ & 188.7 & 0.102 \\
\hline Years of illness $^{\mathrm{a}}$ (mean years, SD) & $15.5(10.7)$ & $20.0(10.8)$ & 73.1 & 0.032 & $19.0(12.2)$ & 158.4 & 0.050 & $18.4(12.6)$ & 221.1 & 0.054 \\
\hline Hospitalizations $^{\mathrm{a}}$ (mean $N, \mathrm{SD}$ ) & $2.8(5.0)$ & $2.5(3.1)$ & 120.4 & 0.548 & $1.8(2.5)$ & 137.2 & 0.079 & $1.9(2.8)$ & 125.1 & 0.075 \\
\hline Diagnosis $^{\mathrm{b}}$ & & & 2 & 0.279 & & 1 & 0.650 & & 1 & 0.925 \\
\hline Bipolar I $(N, \%)$ & $64(63)$ & $31(72)$ & & & $58(66)$ & & & $107(63)$ & & \\
\hline Bipolar II $(N, \%)$ & $38(37)$ & $12(28)$ & & & $30(34)$ & & & $62(37)$ & & \\
\hline Gender $^{\mathrm{b}}$ & & & 1 & 0.423 & & 1 & 0.705 & & 1 & 0.570 \\
\hline Female $(N, \%)$ & $71(70)$ & $27(63)$ & & & $59(67)$ & & & $112(66)$ & & \\
\hline Male $(N, \%)$ & $31(30)$ & $16(37)$ & & & $29(33)$ & & & $57(34)$ & & \\
\hline Education level $^{\mathrm{b}}$ & & & 2 & 0.544 & & 2 & 0.736 & & 2 & 0.423 \\
\hline High school $(N, \%)$ & $13(14)$ & $3(8)$ & & & $9(11)$ & & & $18(11)$ & & \\
\hline Some college $(N, \%)$ & $35(38)$ & $15(37)$ & & & $29(35)$ & & & $51(32)$ & & \\
\hline College graduate $(N, \%)$ & $45(48)$ & $22(55)$ & & & $44(54)$ & & & $91(57)$ & & \\
\hline Employment status ${ }^{\mathrm{b}}$ & & & 2 & 0.169 & & 2 & 0.030 & & 2 & 0.103 \\
\hline Disabled $(N, \%)$ & $21(24)$ & $11(28)$ & & & $20(25)$ & & & $37(23)$ & & \\
\hline Working full-time $(N, \%)$ & $51(59)$ & $17(42)$ & & & $33(41)$ & & & $75(48)$ & & \\
\hline Other $(N, \%)$ & $15(17)$ & $12(30)$ & & & $27(34)$ & & & $46(29)$ & & \\
\hline Marital status ${ }^{\mathrm{b}}$ & & & 2 & 0.928 & & 2 & 0.928 & & 2 & 0.927 \\
\hline Married $(N, \%)$ & $45(48)$ & $20(50)$ & & & $36(46)$ & & & $78(49)$ & & \\
\hline Single $(N, \%)$ & $34(37)$ & $15(37)$ & & & $30(38)$ & & & $59(37)$ & & \\
\hline Divorced $(N, \%)$ & $14(15)$ & $5(13)$ & & & $13(16)$ & & & $21(13)$ & & \\
\hline $\begin{array}{l}\text { Number of daily medications }{ }^{\mathrm{a}} \text { (mean } N \text {, } \\
\text { SD) }\end{array}$ & $2.8(1.6)$ & $2.7(1.4)$ & 86.8 & 0.769 & $2.6(1.6)$ & 184.7 & 0.310 & $2.6(1.5)$ & 206.3 & 0.183 \\
\hline Taking any mood stabilizer ${ }^{\mathrm{b}}(N, \%)$ & $80(78)$ & $36(84)$ & 1 & 0.467 & $69(78)$ & 1 & 0.997 & $133(79)$ & 1 & 0.959 \\
\hline Taking lithium ${ }^{\mathrm{b}}(N, \%)$ & $30(29)$ & $11(26)$ & 1 & 0.640 & $20(23)$ & 1 & 0.297 & $40(24)$ & 1 & 0.295 \\
\hline Taking valproate $^{\mathrm{b}}(N, \%)$ & $24(24)$ & $11(26)$ & 1 & 0.792 & $20(23)$ & 1 & 0.896 & $34(20)$ & 1 & 0.507 \\
\hline Taking lamotrigine $^{\mathrm{b}}(N, \%)$ & $34(33)$ & $14(33)$ & 1 & 0.928 & $29(33)$ & 1 & 0.956 & $64(38)$ & 1 & 0.451 \\
\hline Taking antidepressant ${ }^{\mathrm{b}}(N, \%)$ & $50(49)$ & $23(54)$ & 1 & 0.623 & $44(50)$ & 1 & 0.893 & $86(51)$ & 1 & 0.766 \\
\hline Taking antipsychotic ${ }^{\mathrm{b}}(N, \%)$ & $54(53)$ & $17(40)$ & 1 & 0.140 & $33(38)$ & 1 & 0.033 & $66(39)$ & 1 & 0.026 \\
\hline Taking benzodiazepine $^{\mathrm{b}}(N, \%)$ & $27(27)$ & $11(26)$ & 1 & 0.911 & $20(23)$ & 1 & 0.551 & $35(21)$ & 1 & 0.274 \\
\hline Taking sleep medication ${ }^{\mathrm{b}}(N, \%)$ & $10(10)$ & $3(7)$ & 1 & 0.586 & $5(6)$ & 1 & 0.293 & $8(5)$ & 1 & 0.104 \\
\hline
\end{tabular}

a Student's $t$ test, equal variances not assumed

b Pearson Chi-Square test

results were very similar to our prior findings, with the current sample about double in size [4].

The majority of symptomatic days occurred outside of a DSM-IV episode, which agrees with prior longitudinal studies of bipolar disorder [16-18]. With a 4-day minimum length, more than half of the days of hypomania occurred outside of an episode. Even with a 2-day minimum length, one-third of all hypomania remained outside of an episode. Single days of hypomania were so frequent that with a length criterion of 1-day, 271 patients $(69 \%)$ experienced an episode. For any episode length, the percent of hypomanic days occurring outside of an episode did not differ between bipolar I and II disorder. Additionally, about $60 \%$ of the reported days of depression occurred outside of an episode regardless of the length criterion for hypomania.

In prior research based on clinician interviews, and including patients with depressive disorders, most hypomania lasted for 1-3 days [1, 2, 8, 9, 19], which is consistent with the current findings. The high frequency of brief hypomania in this sample suggests that if the length criterion for an episode of hypomania is decreased, the frequency criterion should be increased, as frequency may 
be an important dimensional aspect of brief hypomania. The current study cannot address whether decreasing the minimum length criterion for an episode of hypomania would improve the accuracy of the diagnosis of bipolar disorder.

While most of the hypomania reported in this study was brief and self-limited, in a sample of patients who are all receiving treatment, the high frequency of hypomanic symptoms occurring outside of a DSM-IV episode is troublesome. Although some patients, especially with bipolar II disorder, report improved functioning when experiencing mild hypomania $[20,21]$, subsyndromal or residual symptoms of mania are associated with an increased risk of relapse [22, 23]. Furthermore, cumulative morbidity in bipolar disorder, even from mild symptoms, may be associated with more functional impairment than the total number of episodes [12, 24, 25]. Hypomania is associated with a high risk for divorce [3], and over a lifetime, an increased use of health services, an increased need for social welfare, and an increase in suicidal behaviors [6]. Clinicians should probe patients with bipolar disorder for brief hypomanic episodes, and assess whether these are interfering with everyday functioning. One clinical benefit of daily charting may be to improve the detection and monitoring of subsyndromal mood symptoms.

As found in our earlier study [4], there was no significant difference in the occurrence of 1-day hypomania between patients with bipolar I and bipolar II disorders. Additionally, there were no significant demographic differences between patients who met the 4-day length criterion and those who only experienced a hypomanic episode with a shorter length criterion. It does not appear that either experiencing brief hypomanic episodes or single days of hypomania are useful parameters for distinguishing subgroups within a sample of patients who meet the DSM-IV criteria for bipolar disorder.

There are several limitations to this analysis. With a naturalistic design, the patients in this sample varied in disease severity, phase of illness and medications taken. All mood ratings used in this analysis were self-reported, and the ChronoRecord mood rating does not measure the specific components of hypomania/mania or depression. While a ChronoRecord rating of mania/hypomania best reflects activation levels [13], this is not a specific measure of overactivity which may be a core feature of hypomania $[2,8,26]$. Additionally, clinical diagnosis of a hypomanic episode traditionally emphasizes behavioral manifestations and functional impairment. Daily access to a home computer was required throughout the study. However, the demographic profile of the patients who use ChronoRecord is similar to that in other studies of bipolar disorder [12]. This study did not include patients with bipolar disorder who were not receiving treatment, and patients who never experience hypomania that lasts for 4 days. Finally, this study did not address the issues of differentiating brief hypomania from normal mood elevation, or bipolar disorder from unipolar depression.

In conclusion, decreasing the episode length criterion for hypomania will significantly increase the number of patients with episodes and the aggregate number of episodes. Frequency may be an important dimensional aspect of brief hypomania. Decreasing the episode length criterion was not useful for distinguishing subgroups within this sample. Clinicians should probe patients with bipolar disorder for brief hypomanic episodes.

Open Access This article is distributed under the terms of the Creative Commons Attribution Noncommercial License which permits any noncommercial use, distribution, and reproduction in any medium, provided the original author(s) and source are credited.

\section{References}

1. Akiskal HS (1996) The prevalent clinical spectrum of bipolar disorders: beyond DSM-IV. J Clin Psychopharmacol 16(Suppl 1): $4 \mathrm{~S}-14 \mathrm{~S}$

2. Akiskal HS, Benazzi F (2005) Optimizing the detection of bipolar II disorder in outpatient private practice: toward a systematization of clinical diagnostic wisdom. J Clin Psychiatry 66:914-921

3. Angst J (1998) The emerging epidemiology of hypomania and bipolar II disorder. J Affect Disord 50:143-151

4. Bauer M, Grof P, Rasgon NL, Marsh W, Munoz RA, Sagduyu K, Alda M, Quiroz D, Glenn T, Baethge C, Whybrow PC (2006) Selfreported data from patients with bipolar disorder: impact on minimum episode length for hypomania. J Affect Disord 96:101-105

5. Bauer M, Glenn T, Grof P, Schmid R, Pfennig A, Whybrow PC (2010) Subsyndromal mood symptoms: a useful concept for maintenance studies of bipolar disorder. Psychopathology 43:1-7

6. Judd LL, Akiskal HS (2003) The prevalence and disability of bipolar spectrum disorders in the US population: re-analysis of the ECA database taking into account subthreshold cases. J Affect Disord 73:123-131

7. Okasha A (2009) Would the use of dimensions instead of categories remove problems related to subthreshold disorders? Eur Arch Psychiatry Clin Neurosci 259(Suppl 2):S129-S133

8. Angst J, Gamma A, Benazzi F, Ajdacic V, Eich D, Rössler W (2003) Toward a re-definition of subthreshold bipolarity: epidemiology and proposed criteria for bipolar-II, minor bipolar disorders and hypomania. J Affect Disord 73:133-146

9. Benazzi $F$ (2001) Is 4 days the minimum duration of hypomania in bipolar II disorder? Eur Arch Psychiatry Clin Neurosci 251:32-34

10. Cassano GB, Akiskal HS, Savino M, Musetti L, Perugi G (1992) Proposed subtypes of bipolar II and related disorders: with hypomanic episodes (or cyclothymia) and with hyperthymic temperament. J Affect Disord 26:127-140

11. DSM-V proposed revisions. http://www.dsm5.org/Proposed Revisions/Pages/proposedrevision.aspx?rid=426\#. Accessed 6 July 2010

12. Bauer M, Glenn T, Grof P, Rasgon NL, Marsh W, Sagduyu K, Alda M, Lewitzka U, Sasse J, Kozuch-Krolik E, Whybrow PC (2009) Frequency of subsyndromal symptoms and employment status in patients with bipolar disorder. Soc Psychiatry Psychiatr Epidemiol 44:515-522 
13. Bauer M, Grof P, Gyulai L, Rasgon N, Glenn T, Whybrow PC (2004) Using technology to improve longitudinal studies: selfreporting with ChronoRecord in bipolar disorder. Bipolar Disord 6:67-74

14. Bauer M, Wilson T, Neuhaus K, Sasse J, Pfennig A, Lewitzka U, Grof P, Glenn T, Rasgon N, Bschor T, Whybrow PC (2008) Selfreporting software for bipolar disorder: validation of ChronoRecord by patients with mania. Psychiatry Res 159:359-366

15. Denicoff KD, Smith-Jackson EE, Disney ER, Suddath RL, Leverich GS, Post RM (1997) Preliminary evidence of the reliability and validity of the prospective life-chart methodology (LCM-p). J Psychiatr Res 31:593-603

16. Benazzi F, Akiskal H (2006) The duration of hypomania in bipolar-II disorder in private practice: methodology and validation. J Affect Disord 96:189-196

17. Judd LL, Akiskal HS, Schettler PJ, Endicott J, Maser J, Solomon DA, Leon AC, Rice JA, Keller MB (2002) The long-term natural history of the weekly symptomatic status of bipolar I disorder. Arch Gen Psychiatry 59:530-537

18. Paykel ES, Abbott R, Morriss R, Hayhurst H, Scott J (2006) Subsyndromal and syndromal symptoms in the longitudinal course of bipolar disorder. Br J Psychiatry 189:118-123

19. Wicki W, Angst J (1991) The Zurich Study. X. Hypomania in a 28- to 30-year-old cohort. Eur Arch Psychiatry Clin Neurosci 240:339-348

20. Jamison KR, Gerner RH, Hammen C, Padesky C (1980) Clouds and silver linings: positive experiences associated with primary affective disorders. Am J Psychiatry 137:198-202
21. Judd LL, Akiskal HS, Schettler PJ, Endicott J, Leon AC, Solomon DA, Coryell W, Maser JD, Keller MB (2005) Psychosocial disability in the course of bipolar I and II disorders: a prospective, comparative, longitudinal study. Arch Gen Psychiatry 62:1322-1330

22. Judd LL, Schettler PJ, Akiskal HS, Coryell W, Leon AC, Maser JD, Solomon DA (2008) Residual symptom recovery from major affective episodes in bipolar disorders and rapid episode relapse/ recurrence. Arch Gen Psychiatry 65:386-394

23. Perlis RH, Ostacher MJ, Patel JK, Marangell LB, Zhang H, Wisniewski SR, Ketter TA, Miklowitz DJ, Otto MW, Gyulai L, Reilly-Harrington NA, Nierenberg AA, Sachs GS, Thase ME (2006) Predictors of recurrence in bipolar disorder: primary outcomes from the Systematic Treatment Enhancement Program for Bipolar Disorder (STEP-BD). Am J Psychiatry 163:217-224

24. Gitlin MJ, Swendsen J, Heller TL, Hammen C (1995) Relapse and impairment in bipolar disorder. Am $J$ Psychiatry 152:1635-1640

25. Goldberg JF, Harrow M (2004) Consistency of remission and outcome in bipolar and unipolar mood disorders: a 10-year prospective follow-up. J Affect Disord 81:123-131

26. Bauer MS, Crits-Christoph P, Ball WA, Dewees E, McAllister T, Alahi P, Cacciola J, Whybrow PC (1991) Independent assessment of manic and depressive symptoms by self-rating. Scale characteristics and implications for the study of mania. Arch Gen Psychiatry 48:807-812 